\title{
Self Catheterization: Urinary Complications and the Social Resettlement of Spinal Cord Injured Patients ${ }^{\star}$
}

E. Berard, M.D., J. Depassio, M.D., N. Pangaud, M.D. and J. Landi, M.D. Sce de reeducation Fonctionnelle Hopital R. Sabran F. 83406, Giens/Hyeres, France

Key Words: Self Catheterization; Paraplegia

A well-balanced bladder is characterized by complete voiding associated with an acceptable social continence, without any complications involving the upper or lower urinary tract. Studying 100 cases of spinal cord injuries, the authors demonstrate the advantages of self catheterization to avoid various urinary complications, and to obtain a better social resettlement. A well balanced bladder is effective within 260 days for self catheterizating patients against 503 days for other patients.

Stenosis of the urethral sphincter occurs in 3 per cent of the patients, being the same rate in self catheterizating patients as in the population as a whole.

Urolithiasis occurred in 9 per cent of the self catheterizating patients against 25 per cent in the population as a whole.

None of the self catheterizating patients had a genital infection, against 8.8 per cent in the population as a whole.

Urinary infections are common in 50 per cent of hospitalised patients with the same rate among both populations of self catheterizating and other patients. This frequency is only 25 per cent of the self catheterizating patients after discharge home.

Bladder-neck obstructions are present in 6 per cent of the whole population without any difference in the two populations.

Vesico-ureteral reflux is present in 9 per cent of the self catheterizating patients against 6 per cent in the whole population.

Urethral injuries occur in 10 per cent of the self catheterizating patients against 3.5 per cent for non-self catheterizating patients.

In spite of the latter two complications, self catheterization allows a better social and sexual resettlement, avoiding most of the other urinary complications (62 per cent of self catheterizating patients being at work or attempting professional rehabilitation in the 5 years following spinal cord injury). 